\title{
The importance of corporate brand personality traits to a successful 21st century business
}

Received (in revised form): 22nd April, 2006

\begin{abstract}
KEVIN LANE KELLER
is the EB Osborn Professor of Marketing at Tuck School of Business, Dartmouth College. Keller has served as brand confidant to marketers for some of the world's most successful brands, including Disney, Ford, Intel, Levi Strauss, Nike, Accenture and Starbucks. He wrote the textbook Strategic Brand Management: Building, Measuring and Managing Brand Equity and co-authored with Philip Kotler the textbook Marketing Management.
\end{abstract}

\section{KEITH RICHEY}

is an independent consultant working in New York. He holds a joint Master's degree in Global Media and Communication from the University of Southern California and the London School of Economics.

\section{Keywords}

corporate branding;

corporate image; corporate values; brand personality; brand personality traits; corporate brand personality
Kevin Lane Keller

Professor of Marketing,

Tuck School of Business,

Dartmouth College, Hall

Hanover,

$\mathrm{NH} 03755$, USA

Tel: + I6036460393

E-mail: kevin.keller@dartmouth. edu

\section{Abstract}

Brand personality has been defined as the human characteristics or traits that can be attributed to a brand. Corporate brand personality is a form of brand personality specific to a corporate brand. Unlike a product brand personality that typically relates to consumers and user imagery for a specific product brand, a corporate brand personality can be defined in terms of the human characteristics or traits of the employees of the corporation as a whole. A corporate brand personality will reflect the values, words, and actions of all employees of the corporation. $A$ successful 2 Ist century firm must carefully manage its corporate brand personality. The three core dimensions of corporate brand personality and two traits for each dimension that are crucial for marketplace success are outlined as Passionate and Compassionate (Heart), Creative and Disciplined (Mind) and Agile and Collaborative (Body). These traits have an interactive effect such that the effects of one trait can be enhanced by the existence of another.

Journal of Brand Management (2006) 14, 74-81. doi:10.1057/palgrave.bm.2550055

\section{INTRODUCTION}

As markets continue to mature and competition within industries grows fiercer, companies will not succeed purely on the basis of what products or services they offer. Although these core functions of the business are unquestionably still crucial, other aspects such as company culture and corporate citizenship have increased in relative importance in determining a company's ability to compete. ${ }^{1-3}$ As a result, the success of a 21 st century business will be defined as much by who it is as what it does., Historically, the identity of a company resulted solely as the consequence of what that company did. Increasingly, the reverse will be true, and the former will impact the latter.

What a company is and how it presents itself to the consumer are defined by its corporate brand personality. Corporate brand personality is a form of brand personality specific to a corporate brand. Brand personality is understood as the human characteristics or traits that can be attributed to a brand. ${ }^{6}$ The way brand personality is commonly explored in consumer research is by asking questions such as: 'If the brand were to come alive as a person, what would it be like? What would it do? Where would it live? What would it wear? Who would it talk to if it went to a party (and what would it talk about)?' 
Although the concept of brand personality is relevant to both product brands and corporate brands, there is an important distinction that can be drawn between the two types of brands that affects how the brand personality concept should be applied. A corporate brand is distinct from a product brand in that a corporate brand can encompass a much wider range of associations. ${ }^{6}$ For example, a corporate brand may be more likely to invoke associations based on people and relationships; programs and values; and corporate credibility; as well as on common products and their shared attributes or benefits. Procter \& Gamble is an example of a corporate brand that has a more broadly defined and differently composed set of associations than those associations of the product brands it owns (eg Tide, Pringles, Mr Clean, Pantene, Iams, etc.).

Consequently, corporate brands will typically have a set of personality traits that is broader and differently composed than the set of personality traits for each product brand owned. By its nature, a product brand is defined by what it does and represents, whereas a corporate brand is defined as much by who it is as what it does. Unlike a product brand personality that typically relates to consumers and user imagery for a specific product brand, a corporate brand personality can be defined in terms of the human characteristics or traits of the employees of a corporation as a whole. A corporate brand personality will therefore reflect the values, words and actions of employees, individually and collectively.

Importantly, a successful 21st century firm must carefully manage its corporate brand personality. The corporate brand personality should reflect the corporate values held by the organisation. For example, if environmental stewardship is one of a company's core values, then attributes such as 'responsible' and 'caring (for the environment)' would be reflected in its set of brand personality traits. In this way, the corporate brand personality is shaped by the corporate values. A company's corporate brand personality traits as seen by consumers and the general public should be aligned with the company's internally espoused values.

Only once a corporation solidifies an appropriate set of personality traits that are consistent with its values and drive employee behaviours can it attain sustainable success against its competitors. In this paper, a perspective on corporate brand personality traits is offered. Specifically, it is contended that there are three key sets of traits that collectively define corporate brand personality. Maximising performance of the organisation on these three sets of traits is therefore crucial for business success in the 21 st century.

\section{CORPORATE BRAND PERSONALITY TRAITS}

Externally, corporate brands can establish a number of valuable associations in the minds of customers and other key constituents that can help to differentiate the brand, such as common product attributes, benefits or attitudes; people and relationships; programmes and values; and corporate credibility. ${ }^{7-10}$ Regardless of how it is constituted, a corporate image will depend on a number of factors, such as the products a company makes, the actions it takes, and the manner in which it communicates to consumers.

A key component of the corporate image is the corporate brand personality. In the past, brand personality has been studied at the product level. Aaker ${ }^{11}$ examined the brand personality attributed to 60 US product brands and found they fall into five main clusters: (1) sincerity, (2) excitement, (3) competence, (4) sophistication and (5) ruggedness (see also Aaker et al.,). ${ }^{12}$ 


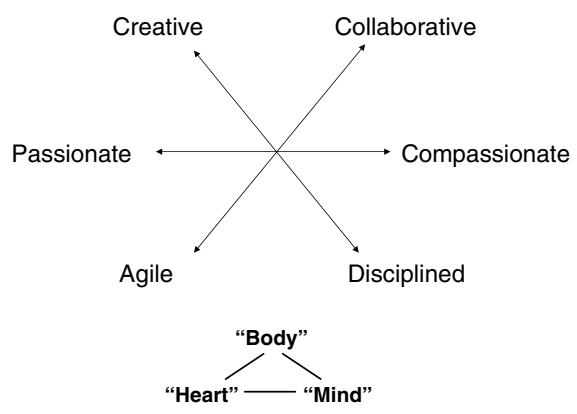

Figure I Corporate personality traits.

Product brand personality is strongly defined in terms of user imagery - characteristics of consumers who use or are intended to use a brand. Brand personality is seen as a means for consumers to express their actual or idealised self-image.

Corporate brand personality, however, is much more about perceptions of employees - both senior management and customer-facing-that make up the company as well as the organisation as a whole. Corporate brand personality reflects the values, actions, and words of all employees of the corporation. In a business-to-business setting, corporate brand personality is often determined by direct contact with a wide range of employees. As a result of the different focus, corporatelevel traits transcend individual products that the firm sells and the five product brand personality dimensions.

One useful means to characterise corporate brand personality dimensions is in terms of the tripartite view of attitudes, ${ }^{13}$ which consists of affective (feelings), cognitive (thoughts) and conative (actions) dimensions. Specifically, we believe that the corporate personality traits of a successful 21st century business can be grouped into three dimensions related to the 'heart,' the 'mind' and the 'body' (see Figure 1). These dimensions reflect three distinct sets of personality traits that can guide employees in the organisation and influence how the company will be viewed by others.

- The 'heart' of the company is comprised of two traits: passionate and compassionate. The company must be passionate about serving its customers and competing in the market and must have compassion for employees, stakeholders, and members of the communities in which it operates.

- The 'mind' of the company contains two traits: creative and disciplined. A successful company must be creative in its approach to serving its customers and winning in the market, while also adopting a disciplined approach that ensures appropriate and consistent actions across the organisation.

- The 'body' of the company is made up of two traits: agile and collaborative. The successful company must possess the agility to profitably react to changes in the market and also employ a collaborative approach that ensures it works well together inside and outside the company toward common goals.

Note that the identification of these three core dimensions of corporate brand personality is broadly consistent with earlier academic work that empirically analyzed approaches to corporate identity research and identified three core dimensions of the 'Corporate Identity Mix:' Soul, Mind and Voice. ${ }^{14,15}$

Next, we discuss these three corporate brand personality dimensions in detail. For each of the three dimensions, two additional sub-dimensions are identified that capture the primary corporate personality traits within these dimensions.

\section{Heart: Passion and Compassion}

The 'heart' of the organisation involves passion and compassion. Employees of 
successful 21st century firms must be passionate about the company, its brands, and their jobs. ${ }^{16,17}$ If they do not feel strongly about what they do, then it will be difficult to motivate them to adopt other vital corporate personality traits. The passion felt by employees for their specific roles in the company must extend to their business, the industry in which it competes, and the products and services it offers customers. It is especially imperative that employees be passionate about what they do for their customers. As customers are the core asset of any company, every employee must have a strong desire to assist the company in its commitment to the customer. For example, GE ensured that the customer's interests would remain a top priority internally by establishing the 'Voice of the Customer' process for identifying what matters most to customers and allocating resources accordingly.

The 21st century firm must care deeply about all its stakeholders, from its customers to its employees to the members of the communities in which it does business. Customer care, for example, can be demonstrated with customer rewards programs, enhanced customer service, or by responding to customer needs with new products and services. Citibank's 'Thank You' rewards program for its banking customers is a recent example of a customer care initiative. Employee care can be manifested by enhanced benefits, employee recognition programs, or profit participation and shareholding schemes such as Starbucks 'Bean Stock' program, which gives every Starbucks employee shares in the company. Community care can be demonstrated by corporate social responsibility initiatives or cause-related marketing efforts such as Avon's Walk for Breast Cancer. Additionally, the firm must show care for the environment, which can be shown through efforts to use clean energy sources in manufacturing or programs to reduce the pollution produced by the finished products themselves. Ben \& Jerry's demonstrated its care for the environment by splitting the traditional financial bottom line into a 'double' bottom line, which included a measurement of the environmental impact of their products and processes.

Passion provides the internal drive for employees, but it must be tempered by a concern for others via compassion. ${ }^{18}$ Nike is an outstanding example of a company whose passion for athletics and athletes has fuelled great marketing success, but is compassionate to others in many different ways. Nike exhibits compassion to society as a whole through their various community initiatives such as the NikeGO program to 'get kids moving and give them a means to do it' and Zoneparcs in the UK to transform playtime at UK primary schools; environmental initiatives such as Nike Considered, which uses different footwear materials and construction to minimise waste and toxic substances, and the Nike Reuse-A-Shoe recycling program; and corporate responsibility initiatives through best practice methods in supply chain management and involvement with the Global Alliance.

\section{Mind: Creativity and Discipline}

The 'mind' of a successful business must be creative but disciplined. In particular, 21 st century firms must possess creativity to overcome the trade-offs inherent in virtually all aspects of business. In many ways, the most fundamental challenge of management is how to reconcile or address the many potential tradeoffs that can exist in making marketing and other decisions. Figure 2 lists a number of the different possible trade-offs or conflicts that can occur in making strategic, tactical, 


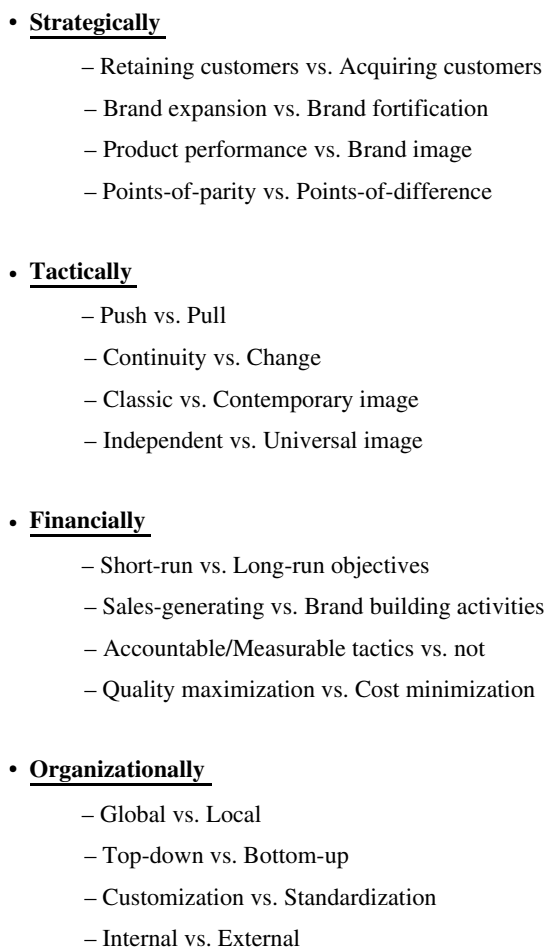

Figure 2 Some marketing trade-offs

financial, or organisational decisions for a company.

For example, a strategic tradeoff occurs between building product performance and crafting an appealing brand image, since these strategies typically require different competencies and skills. Financially, sales-generating and brand-building activities are often in conflict. One of the surest ways to increase sales is to reduce the price, but sustained price reductions may lead to consumer perceptions of the brand as 'discount' or 'cheap', which would detract from brand strength. Additionally, the organisational tradeoff of customisation versus standardisation reflects the fact that increasingly customers desire products and services that are tailored to their specific needs, but it is typically more cost-efficient for companies to produce a standardised version than a customised one. Clearly, trade-offs are pervasive and must be made in the context of constrained - and often fairly limited — resources.

But marketers do not want to necessarily sub-optimise and emphasise one dimension or the other. A better approach would be to 'finesse the difference' and achieve synergy between the two dimensions. Marketing balance in this way could occur by shrewdly reconciling the decision trade-offs - that is by finessing the conflicting dimensions There is virtually no way to do so, however, without creative, imaginative solutions.

For example, creative advertising can be designed that both entertains and sells products, as was the case with the California Milk Processor Board's Got Milk? campaign. Brand equity-building promotions that also move product can be devised, as was the case with Procter \& Gamble's promotion for Ivory soap that reinforced a key attribute of 'floating' and a key benefit of 'purity' while also increasing sales. Robust brand positions can be established that stake out unique competitive territory by simultaneously creating points-of-party and pointsof-difference, such as was the case with Apple's 'The Power to Be Your Best' ad campaign in the mid-1980s which reconciled the seemingly negatively correlated benefits of 'easy to use' (a point of difference) and 'powerful' (a point of parity) in the minds of consumers.

In each of those cases, creativity and innovative approaches overcame tough marketing dilemmas. Innovations must go beyond solving trade-offs, however, to also address other organisational issues. Firms must demonstrate the ability to find new solutions to old problems. For example, Procter \& Gamble, consistently among the most innovative packaged-goods companies, recently created a more efficient way to clean persistent bathroom stains with 
the launch of the Mr Clean Magic Eraser, which contains a specialty chemical foam made by BASF.

A successful firm must also be disciplined in its approach to growing its business, which in itself at times can present a trade-off with creativity. While it is necessary to encourage and maintain creativity in the organisation, this creativity must be focused to a certain degree. A successful firm must concentrate on leveraging its core competencies and maintaining focus on its core business, rather than pursuing any new business opportunity that arises. This can be best achieved by setting appropriate priorities that provide clear direction to all members of the organisation as to what its business goals are and how they can be met.

If firms are to compete successfully in today's rapidly changing marketplace, they must transcend the current status quo and find creative ways to systematically deliver differentiated and unexpected value to consumers. For example, $3 \mathrm{M}$ encourages a culture of innovation by requiring its scientists to spend 15 per cent of their time pursuing research that interests them outside their specific role in the company. As a result, $3 \mathrm{M}$ consistently delivers innovative, creative, and, importantly, differentiated products that bring value to consumers.

With the ' 15 per cent rule,' the company manages the creativity of its employees so that this creativity augments its core business, rather than distracting from it.

To further maintain discipline, the 21st century firm must resist following the latest management fads, since frequently reorganising or restructuring a business to follow untested management philosophies can be distracting and even damaging. Similarly, the firm must avoid the 'grass is greener' syndrome, in which the firm de-emphasises some existing businesses and markets in favour of building new businesses and/or competing in new markets that seem more attractive for reasons such as that they are growing faster or have fewer competitors. Then, a few years later, the firm repeats the move, shifting again into another new business or market. The firm affected by the 'grass is greener' syndrome overlooks the fact that success cannot be sustained by continually chasing business trends.

\section{Body: Agile and Collaborative}

Finally, the 'body' of the firm involves being agile and collaborative. A successful 21 st century firm must possess the agility to capture and deliver value to consumers in the face of challenging market dynamics. Many changes have occurred in the marketing environment in recent years. Undoubtedly, the marketing environment will continue to evolve and change, often in very significant ways, in the coming years. Shifts in consumer behaviour, competitive strategies, government regulations or other aspects of the marketing environment can profoundly affect the fortunes of a firm. Besides these external forces, the firm itself may engage in a variety of activities and changes in strategic focus or direction that may necessitate minor or major adjustments in the way that its brands are being marketed.

Consequently, effective brand management requires proactive strategies designed to at least maintain - if not actually enhance- -brand equity in the face of all of these different forces. The firm must be able to move forward quickly to take advantage of new opportunities in the market. Google is currently capitalising on its agility to move rapidly into new markets such as IP telephony, wireless internet access, and video content provision as well as challenging entrenched competitors in established markets such as e-commerce, publishing, desktop software and classified ads. 
The 21st century firm must also adapt its business model to changing conditions. As noted above, it is important to apply the appropriate level of discipline to ensure that these changes do not dilute the strength of its core business. To be truly successful in the long term, the 21st century firm must be proactive, rather than reactive. Being proactive requires that a firm anticipate what changes will be necessary in the future and proactively address them. Innovation and relevance in all that it does will require much agility by the firm as it ensures that it continually moves forward, but does so in the right direction.

Finally, the successful 21 st century firm must encourage collaboration among its employees and seek a closely collaborative atmosphere with its business partners. Increasingly, a key goal of marketing is to develop deep, enduring relationships with all people or organisations that could directly or indirectly affect the success of the firm's marketing activities.

Internally, the firm must foster a culture of inter-departmental teamwork. Only when employees willingly seek opportunities to collaborate can a firm develop the agility to overcome business challenges. Externally, the firm must develop a network of partners that offer complementary assets and competencies, have common corporate values and beliefs, and jointly create synergistic effects. For example, Wal-Mart invites close collaboration from its biggest suppliers by requiring them to permanently staff teams at the retail giant's Bentonville, Arkansas headquarters.

Successful collaborations result from relationship marketing that cultivates the right kind of relationships with the right constituent groups. Four key constituents for marketing are customers, employees, marketing partners (channels, suppliers, distributors, dealers, university scientists, agencies, etc.); and members of the financial community (shareholders, investors, analysts). Relationship marketing builds strong economic, logistical and social ties among all these relevant parties.

Successful relationship marketing offers the potential of smoother operations and superior customer solutions. The ultimate outcome of relationship marketing is the building of a marketing network-the company and all its supporting constituents and stakeholders with whom it has built mutually beneficial relationships. ${ }^{19}$ Marketing networks are invaluable company assets. Increasingly, competition is not between companies but between marketing networks. Winning companies will be those that build better net-works, in part through a strong spirit of collaboration.

Developing strong relationships requires understanding the capabilities and resources of different groups, as well as their needs, goals and desires. Each party must be treated differently. Rich, multifaceted relationships with key constituents create the foundation for a mutually beneficial arrangement for both parties.

\section{CONCLUSIONS}

\section{A whole greater than the sum of the parts}

A corporate brand personality is defined in terms of three main dimensions, each of which can be defined in terms of two key traits: the 'heart' (passionate and compassionate), the 'mind' (creative and disciplined) and the 'body' (agile and collaborative). Importantly, the effects of these three pairs of corporate personality traits are enhanced by each other. In other words, corporate personality traits can have a multiplicative or interactive effect, not an additive effect.

For example, passion can be the engine for creativity. Employees who live the brand and are close to their customers are more likely to energetically pursue new 
solutions. Creativity, in turn, facilitates agility, as firms are better able to respond and react appropriately. As another example, being disciplined allows for more productive collaborations as the rules of the game are clearly established between partners. In short, a corporate personality that maximises these three dimensions and six traits should be better able to create valuable synergistic effects.

One profitable direction for additional research study is to profile the conditions favouring these synergistic effects. What circumstances must prevail to maximise these interactions? It will also be useful to relate these corporate personality dimensions to other corporate image dimensions, for example corporate credibility and associated perceived expertise, trustworthiness and likeability.

In closing, it is important to emphasise that the corporate personality starts with the company's employees, who bring this personality to life and actually determine who a company is. A company can instill the right values and personality attributes in its people by establishing corporate-wide values for everyone to live by, investing in recruiting and training, communicating objectives openly and listening to its employees. For many firms, the employees are the face of the company to the consumer and it is therefore imperative that they embody the corporate personality the firm aspires to build. If everyone in a company acts with 'heart,' 'mind' and 'body', then the company will be in a better position to succeed in the 21 st century.

\section{Acknowledgments}

Thanks are extended to John Hayes, Chief Marketing Officer, American Express, for inspiring this article.

\section{References}

(1) Brown, T. J. (1998) 'Corporate associations in marketing: Antecedents and consequences',
Corporate Reputation Review, Vol. 1, No. 3, pp. 215-233.

(2) Dowling, G. R. (1994) 'Corporate Reputations', Kogan-Page, London.

(3) Fombrun, C. J. (1996) 'Reputation', Harvard Business School Press, Boston.

(4) Keller, K. L. and Aaker, D. A. (1998) 'Corporatelevel marketing: The impact of credibility on a company's brand extensions', Corporate Reputation Review, Vol. 1, No. 4 (August), pp. 356-378.

(5) Schultz, M., Antorini, Y. M. and Fabian, F. C., (eds) (2005) 'Corporate branding: Purpose, people, and processes', Copenhagen Business School Press, Herndon, VA.

(6) Keller, K. L. (2003) 'Strategic brand management,' 2nd edn, Prentice Hall, Upper Saddle River, NJ.

(7) Barich, H. and Philip, K. (1991) 'A framework for image management', Sloan Management Review, Vol. 32, No. 2 (Winter), pp. 94-104.

(8) Gregory, J. (1997) 'Leveraging the Corporate Brand', NTC Press, Chicago.

(9) Schultz, M., Mary, J. H. and Morgan ,H. L., (eds.) (2000) 'The expressive organization: Linking identity, reputation, and the corporate brand', Oxford University Press, New York.

(10) Upshaw, L. B. and Earle, L.T. (2000) 'The Masterbrand Mandate', John Wiley \& Sons, New York.

(11) Aaker, J. L. (1997) 'Dimensions of brand personality', Journal of Marketing Research, Vol. 34, No. 3 (August), pp. 347-357.

(12) Aaker, J. L., Yeronica, B. M. and Jordi, G. (2001) 'Consumption symbols as carriers of culture: A study of Japanese and Spanish Brand Personality Constructs', Journal of Personality and Social Psychology, Vol. 81, No. 3, pp. 492-508.

(13) Thurstone, L. L. (1931) 'Measurement of social attitudes', Journal of Abnormal and Social Psychology, No. 26, pp. 249-269.

(14) Balmer, J. M.T and Soenen, G. B. (1999) 'The acid test of corporate identity management', Journal of Marketing Management, Vol. 15, Nos. 1-3, pp. 69-92.

(15) Hatch, M. J. and Majken, S. (2001) 'Are the strategic stars aligned for your corporate brand?' Harvard Business Review, Vol. 79, No. 2 (February), pp. 129-134.

(16) Ind, N. (2004) 'Living the brand: How to transform every member of your organization into a brand champion,' 2nd edn, Kogan-Page, London.

(17) Pringle, H. and William, G. (2001) 'Brand manners: How to create the self confident organization to live the brand', John Wiley \& Sons, Hoboken, NJ.

(18) Kotler, P. and Nancy, L. (2005) 'Corporate Social Responsibility: Doing the Most Good for Your Company and Your Cause', John Wiley \& Sons, Hoboken, NJ.

(19) Kotler, P. and Kevin, L. K. (2005) 'Marketing Management, 12th edn, Prentice-Hall, Upper Saddle River, NJ. 